\author{
JURNAL PERENCANAAN WILAYAH \\ e-ISSN: $2502-4205$ \\ Vol.6., No.2, Oktober 2021 \\ http://ojs.uho.ac.id/index.php/ppw
}

\title{
Analisis Ketersediaan Air Baku Pada Pdam Tirta Anoa Di Kota Kendari
}

\section{Analysis of Raw Water Availability at The Tirta Anoa PDAM in Kendari City}

\author{
Adiyanto $^{\left.1)^{*}\right)}$, Muhammad Ramli ${ }^{2}$, Hasbillah Syaf ${ }^{3)}$ \\ ${ }^{1)}$ Programstudi Perencanaan Pengembangan Wilayah, Universitas Halu Oleo \\ ${ }^{2)}$ Fakultas Ekonomi dan Bisinis, Universitas Halu Oleo \\ ${ }^{3)}$ Fakultas Teknik Jurusan Teknik Sipil, Universitas Halu Oleo
}

\begin{abstract}
The provision of clean water to meet the needs of the community is something important, and the availability of clean water must be considered in order to meet the needs of the community, especially in Kendari City. This study aims to analyze the availability of raw water at the Regional Water Company (PDAM) Tirta Anoa Kendari City. The method used is the method of raw water availability by using discharge data from the Pohara River and the Wanggu River in 2010-2019. The results of this study are the availability of raw clean water at PDAM Kendari City is the production discharge of 300 ltr/second, the production discharge of Matabondu Springs of 50 l/second, the production discharge of the Wanggu River of 20 l/second, and the Anduonohu spring discharge of 5 ltr. /sec and Anggoeya at 40 liters/sec
\end{abstract}

Keywords: Raw Water, Availability, PDAM

\section{ABSTRAK}

Penyedian air bersih untuk memenuhi kebutuhan masyarakat merupakan sesuatu yang penting, dan ketersediaan air bersih harus diperhatikan agar dapat memenuhi kebutuhan masyarakat, khususnya di Kota Kendari. Penelitian ini bertujuan untuk menganalisis ketersediaan air baku pada Perusahaan Daerah Air Minum (PDAM) Tirta Anoa Kota Kendari. Metode yang digunakan yaitu metode ketersediaan air baku dengan menggunakan data debit Sungai Pohara dan Sungai Wanggu tahun 2010-2019. Hasil Penelitian ini yaitu ketersediaan air bersih baku pada PDAM Kota Kendari adalah debit produksi sebesar 300 ltr/detik, debit produksi Mata Air Matabondu sebesar 50 l/detik, debit produksi Sungai Wanggu sebesar 20 l/detik, dan debit Mata air Anduonohu sebesar 5 ltr/dtk dan Anggoeya sebesar 40 liter/dtk

Kata Kunci : Air Baku, Ketersediaan, PDAM

\section{PENDAHULUAN}

PDAM salah satu unit yang menangani air bersih, namun kondisiya dalam melakukan pelayanan belum optimal dan tahun 2010 terdapat 381 PDAM yang melayani kurang dari 50\% penduduk kota dan $1 \%$ untuk penduduk desa (BPPSPAM, 2010). Hal ini beriringan dengan ketersediaan air baku yang terdapat di Kota Kendari. Unit air baku PDAM Kota Kendari sebanyak 5 Unit yaitu unit air baku Pohara (Sungai Pohara) dengan kapasitas 400 liter/detik, unit air baku Matabondu (Mata Air) dengan kapasitas 100 liter/detik, unit air baku Wanggu (Sungai Wanggu) dengan kapasitas 20 liter/detik, unit air baku Anggoeya (Sungai Anggoeya) dengan kapasitas 40 liter/detik, dan unit air baku Anduonohu (Mata Air) dengan kapasitas 5 liter/detik. Sumber air baku di Kota Kendari digunakan untuk penyediaan air minum. Penyediaan air minum merupakan salah satu kebutuhan dasar dan hak sosial ekonomi masyarakat yang harus dipenuhi oleh Pemerintah, baik itu Pemerintah Daerah maupun Pemerintah Pusat. Ketersediaan air minum merupakan salah satu penentu peningkatan kesejahteraan masyarakat, yang mana diharapkan dengan ketersediaan air 
minum dapat meningkatkan derajat kesehatan masyarakat dan dapat mendorong peningkatan produktivitas masyarakat, sehingga dapat terjadi peningkatan pertumbuhan ekonomi masyarakat. Oleh karena itu, penyediaan sarana dan prasarana air minum menjadi salah satu kunci dalam pengembangan ekonomi wilayah. Thuram (1995) bahwa terpenuhinya kebutuhan akan air bersih merupakan kunci utama bagi perkembangan suatu kegiatan dan menjadi elemen penting bagi keberlanjutan suatu produktivitas perekonomian.

Pengelolaan Sistem Penyediaan Air Minum (SPAM) Kota Kendari dilakukan oleh Perusahaan Daerah Air Minum (PDAM) Tirta Anoa Kota Kendari yang didirikan berdasarkan Peraturan Daerah No. 3 Tahun 1976 Tentang Pendirian Perusahaan Air Minum (PAM) Daerah Kabupaten Tk. II Kendari, dan Peraturan Daerah No. 3 Tahun 2010 Tentang Organisasi PDAM Kota Kendari dan No. 7 Tahun 2010 Tentang Pelayanan Air Minum. PDAM Kota Kendari mempunyai unit produksi dengan kapasitas terpasang sebesar 565 liter/dtk dengan kapasitas produksi sebesar 415 liter/dtk. IPA Punggolaka merupakan Instalasi Pengelolaan Air tertua dan mempunyai kapasitas produksi, realisasi paling besar serta pelanggan yang paling banyak dibandingkan dengan yang lainnya. PDAM Kota Kendari memiliki 5 unit produksi dan 11 reservoir.

Kebutuhan dan ketersediaan air baku pada PDAM Kota Kendari digunakan untuk mendukung pelaksanaan pembangunan Kota Kendari, sebagai upaya maksimalisasi pelayanan kebutuhan penduduk melakukan aktifitasnya dalam hal penyediaan air bersih. Analisis ketersediaan dan kebutuhan air baku pada PDAM Kota Kendari tersebut dimaksudkan untuk menilai besarnya jumlah kebutuhan air baku, ketersediaan air baku dan alokasi peruntukan ruang untuk fasilitas air besih yang dibutuhkan berdasarkan radius pelayanan terhadap peningkatan jumlah penduduk pada akhir tahun 2040. Radius pelayanan yang dimaksud tidak hanya dalam lingkup kawasan penelitian, tetapi berdasarkan fungsi kawasan sebagai pusat pelayanan terhadap keseluruhan wilayah sekitarnya. Penelitian tentang ketersediaan air telah dilakukan sebelumnya pada lokasi berbeda seperti Baco dkk (2017), Syofyan (2017), sehingga ketersediaan air baku perlu diteliti di Kota Kendari, sehingga tujuan dari penelitian ini yaitu menganalisis ketersediaan air baku pada Perusahaan Daerah Air Minum (PDAM) Tirta Anoa Kota Kendari.

\section{METODE PENELITIAN}

\section{Lokasi Penelitian}

Kota Kendari merupakan ibukota Provinsi Sulawesi Tenggara, secara astronomis terletak di bagian Selatan garis khatulistiwa tepatnya di bagian Tenggara Pulau Sulawesi. Secara astronomi, Kota Kendari terletak antara $3^{\circ} 54^{\prime} 40^{\prime \prime}$ dan $4^{\circ} 5^{\prime} 05^{\prime \prime}$ Lintang Selatan (LS) dan membentang dari Barat ke Timur diantara $122^{\circ} 26^{\prime} 33^{\prime \prime}$ dan $122^{\circ} 39$ '14' 'Bujur Timur (BT) (Gambar 1).

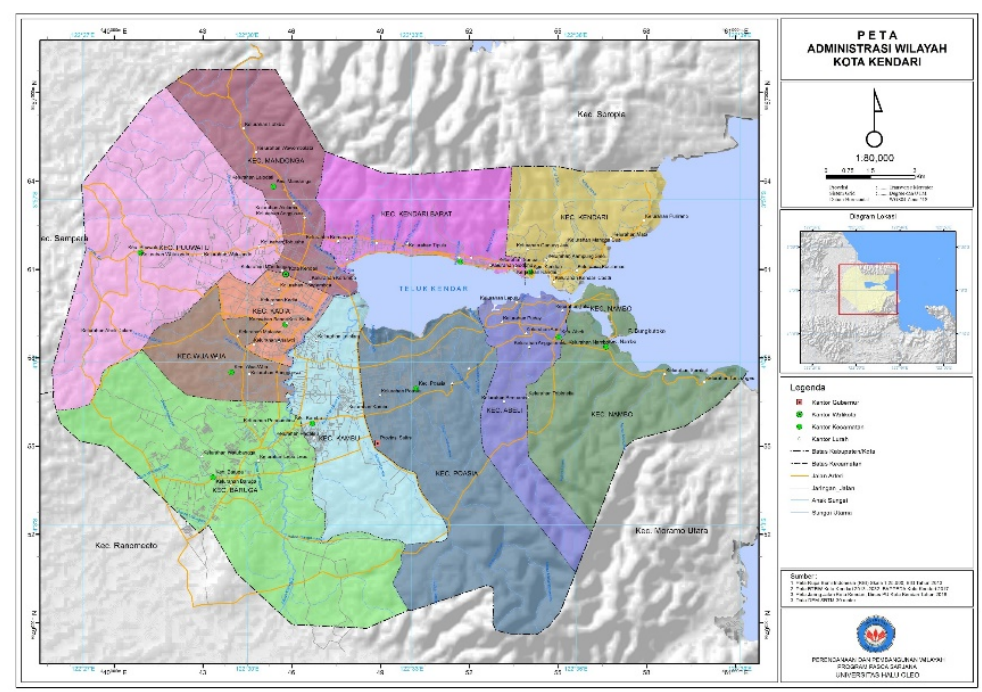

Gambar 1. Lokasi Penelitian 


\section{Jenis dan Sumber Data}

Jenis data yang diperlukan adalah data primer dan data sekunder. Penelitian ini menggunakan data primer berupa debit Sungai Wanggu, debit Sungai Pohara, sedangakan data sekunder yaitu potensi mata air dan debit Sungai Wanggu dan debit Sungai Pohara. Debit sungai menggunakan data primer dan sekunder agar peneliti dapat mebandingkannya.

\section{Teknik Analisis Data}

Penelitian ini dimulai dengan melakukan berbagai analisis data. Data yang telah diperoleh, dianalisis sesuai dengan tujuan penelitian, sehingga diharapkan dapat menjawab permasalahan dan tujuan tujuan penelitian (Tabel 2).

Tabel 2. Matriks Metode Analisis

\begin{tabular}{|c|c|c|c|c|}
\hline No. & Tujuan & Variabel Penelitian & Jenis dan sumber data & $\begin{array}{c}\text { Metode analisis } \\
\text { data }\end{array}$ \\
\hline 1 & $\begin{array}{l}\text { Menganalisis ketersediaan air } \\
\text { baku pada PDAM Tirta Anoa } \\
\text { Kota Kendari }\end{array}$ & $\begin{array}{l}\text { Ketersediaan Air } \\
\text { Baku }\end{array}$ & $\begin{array}{c}\text { Debit Sungai Wanggu, Debit Sungai } \\
\text { Pohara, Potensi mata air } \\
\text { Sumber datanya BWS Sulawesi IV, } \\
\text { BPPW dan PDAM }\end{array}$ & $\begin{array}{l}\text { Analisis } \\
\text { Ketersediaan Air } \\
\text { Baku }\end{array}$ \\
\hline
\end{tabular}

Sumber: Hasil Olah Peneliti, 2020

\section{- Ketersediaan Air}

Ketersediaan prasarana dan pelayanan air bersih penting untuk peningkatan mutu kehidupan masyarakat (Sutrisno, 2004) sehingga perlu dilakukan analisis ketersedian air khususnya di Kota Kendari. Analisis ketersediaan air dilakukan atas dasar hasil analisis debit aliran bulanan selama satu tahun dengan menggunakan data debit Sungai Pohara dan Sungai Wanggu tahun 2010-2019. Ketersediaan air dinyatakan dalam satuan m3/detik dan satuan volume (m3). Ketersediaan air baku untuk PDAM yang digunakan dalam penelitian ini adalah debit air produksi per IKK.

\section{HASIL DAN PEMBAHASAN}

\section{Analisis Ketersediaan Air Baku pada PDAM Tirta Anoa Kota Kendari}

\section{a. Potensi Air Permukaan}

\section{- Sungai Pohara}

Sungai ini terletak kurang lebih $17 \mathrm{~km}$ arah barat Kota Kendari dan masuk dalam wilayah administratif Kecamatan Sampara Kabupaten Konawe provinsi Sulawesi Tenggara. Lebar sungai cukup bervariasi, namun berdasarkan pengukuran dilapangan bagian sungai yang dekat intake PDAM memiliki lebar kurang lebih 80 meter. Sungai Pohara merupakan sungai utama DAS Konaweha yang merupakan DAS terbesar di Sulawesi Tenggara. Luas DAS Konaweha mencapai 697,841 Ha. Saat ini sedimentasi lumpur tambang dan aktifitas eksplorasi perkebunan sawit telah menyebabkan air sungai tercemar.
Saat ini peruntukan terbesar sungai Pohara yaitu sebagai bahan baku PDAM Tirta Anoa Kota Kendari untuk kebutuhan air bersih masyarakat Kota Kendari. Perhitungan kebutuhan air bersih masyarakat Kota Kendari digunakan debit andalan 80\%. Adapun sebaran ketersediaan debit (debit andalan 80\%) berdasarkan data tahun 2015-2019 dapat dilihat pada Tabel 3.

Tabel 3. Debit Sungai Pohara dalam Satu Tahun

\begin{tabular}{llc}
\hline No & Bulan & Debit $\mathbf{( m}^{\mathbf{3}} /$ liter $)$ \\
\hline 1 & Januari & 79,5 \\
2 & Februari & 110,5 \\
3 & Maret & 118,6 \\
4 & April & 142,5 \\
5 & Mei & 281,4 \\
6 & Juni & 158,4 \\
7 & Juli & 79,8 \\
8 & Agustus & 45,4 \\
9 & September & 22,5 \\
10 & Oktober & 13,1 \\
11 & November & 10,1 \\
12 & Desember & 77,2 \\
\hline
\end{tabular}

Sumber: PDAM Tirta Anoa

Tabel 3 dapat diketahui bahwa pada bulan April, Mei dan Juni, debit Sungai Pohara mencapai maksimal, sementara bulan-bulan kering adalah Oktober dan November. Pengukuran yang dilakukan bulan Juli 2019 didapatkan besarnya debit sungai Pohara sebesar 238,8 m3/dtk atau 238.831,3 ltr/detik. Jika dibandingkan dengan kapasitas terpasang PDAM saat ini untuk Sungai Pohara, yaitu 400 ltr/detik dan kapasitas produksi yaitu, 243 
ltr/detik, maka jumlah pemanfaatan debit Sungai Pohara masih sangat kecil dibandingkan dengan debit sungai yang tersedia. Perbandingan kebutuhan air pelanggan PDAM Pohara yaitu sebanyak 15.275 SR atau 76.375 orang yang membutuhkan air sebanyak 105 liter per detik terhadap kapasitas terpasang, yaitu 243 ltr/detik, menunjukkan bahwa kebutuhan air pelanggan tersebut dapat terpenuhi oleh PDAM Pohara. Kinerja penyadiaan air bersih, kualitas air bersih menjadi penting karena paling banyak digunakan oleh masyarakat untuk mendukung kehidupan sehari-hari (Lestari, dkk, 2009).

Berdasarkan pemeriksaan terhadap beberapa kualitas air di Sungai Pohara, diketahui bahwa kualitas Sungai Pohara sebagai air kelas I yang diperuntukkan untuk air bersih dikategorikan baik, karena parameter kualitas airnya berada dibawah standar (Tabel 4).

Tabel 4. Kualitas Air Sungai Pohara

\begin{tabular}{llllllllll}
\hline & $\begin{array}{l}\mathbf{p H} \\
\mathbf{( 0 / 0 0 )}\end{array}$ & $\begin{array}{l}\text { TDS } \\
(\mathbf{m g} / \mathbf{L})\end{array}$ & $\begin{array}{l}\text { Kekeruhan } \\
(\mathbf{N T U})\end{array}$ & $\begin{array}{l}\text { Klorida } \\
\mathbf{( m g} / \mathbf{L})\end{array}$ & $\begin{array}{l}\text { Nitrat } \\
(\mathbf{m g} / \mathbf{L})\end{array}$ & $\begin{array}{l}\text { Nitrit } \\
(\mathbf{m g} / \mathbf{L})\end{array}$ & $\begin{array}{l}\text { Kesadahan } \\
(\mathbf{m g} / \mathbf{L})\end{array}$ & $\begin{array}{l}\mathbf{F e} \\
(\mathbf{m g} / \mathbf{L})\end{array}$ & E-Coli \\
\hline Standar & $6-9$ & 1000 & 50 & 600 & 0,5 & 0,06 & $0,75^{*}$ & 0,3 & 1000 \\
Sampel & 7,13 & 133 & 32,5 & 0,0004 & 0,127 & 0,046 & 0,52 & 0,05 & 29 \\
\hline
\end{tabular}

Sumber: Hasil Olah Data

\section{- Mata Air Matabondu}

Matabondu merupakan mata air alami yang terletak pada Kecamatan Bondoala Kabupaten Konawe. Mata air ini berada ditepian Sungai Konaweha dan terdiri dari beberapa sumber mata air yang dikumpulkan dalan sebuah bangunan penangkap (capturing). Berdasarkan hasil pengukuran debit yang dilakukan pada bulan Juli 2016 didapatkan debit sebesar $0.00514 \mathrm{~m} 3 /$ detil atau 5.14 ltr/dtk.

Pemanfaatan mata air Matabondu sebagai sumber air PDAM baru dimulai tahun 2018. Saat ini mata air Matabondu melayani 627 SR atau 3.135 orang yang membutuhkan air sebanyak 4.3 liter per detik. Jumlah ini jauh diatas jumlah debit yang dihasilkan oleh mata air Matabondu. Berdasarkan pemeriksaan terhadap beberapa kualitas air di mata air Matabondu, diketahui bahwa kualitas mata air Matabondu sebagai air kelas I yang diperuntukkan untuk air bersih dikategorikan baik, karena parameter kualitas airnya berada dibawah standar (Tabel 5).

Tabel 5. Kualitas Air Sungai Matabondu

\begin{tabular}{llllllllll}
\hline & $\begin{array}{l}\mathbf{p H} \\
\mathbf{( 0 / 0 0 )}\end{array}$ & $\begin{array}{l}\text { TDS } \\
(\mathbf{m g} / \mathbf{L})\end{array}$ & $\begin{array}{l}\text { Kekeruhan } \\
\mathbf{( N T U )}\end{array}$ & $\begin{array}{l}\text { Klorida } \\
(\mathbf{m g} / \mathbf{L})\end{array}$ & $\begin{array}{l}\text { Nitrat } \\
(\mathbf{m g} / \mathbf{L})\end{array}$ & $\begin{array}{l}\text { Nitrit } \\
(\mathbf{m g} / \mathbf{L})\end{array}$ & $\begin{array}{l}\text { Kesadahan } \\
(\mathbf{m g} / \mathbf{L})\end{array}$ & $\begin{array}{l}\text { Fe } \\
(\mathbf{m g} / \mathbf{L})\end{array}$ & $\begin{array}{l}\text { E- } \\
\mathbf{C o l i}\end{array}$ \\
\hline Standar & $6-9$ & 1000 & 50 & 600 & 0,5 & 0,06 & $0,75^{*}$ & 0,3 & 1000 \\
Sampel & 6,9 & 418 & 0,86 & 0,0036 & 0,103 & 0,042 & 0,16 & - & - \\
\hline
\end{tabular}

Sumber: Hasil Olah Data

\section{- Sungai Wanggu}

Sungai Wanggu merupakan sungai utama pada DAS Wanggu yang memiliki luas 45,377 Ha. Sungai ini membentang dari barat daya pengunungan Watu ke arah utara yang masuk daerah administratif Konawe Selatan. Sungai ini kemudian bermuara pada teluk Kendari. Panjang sungai Wanggu dari hulu hingga ke muara (teluk Kendari) sekitar 75 km. Lebar sungai cukup bervariasi dimana lebar sungai sekitar intake PDAM unit Wanggu kurang lebih $60 \mathrm{~m}$. Sebagian besar aliran sungai Wanggu berada pada daerah padat pemukiman penduduk,tambak dan areal pertanian. Dari hasil pembangunan yang sedemikian pesat pada daerah pengaliran sungai Wanggu, terjadi perubahanperubahan pola tanam dan tata guna lahan seperti penggunaan lahan usaha dan penggunaan lahan untuk pemukiman yang cukup cepat sehingga menimbulkan permasalahan pada daerah pengaliran sungai tersebut. Perubahan lahan yang paling mencolok terjadi di daerah aliran sungai Wanggu bagian tengah dan bagian hilir. Dibagian tengah daerah aliran sungai terdapat lahan rawa yang sudah beralih fungsi menjadi lahan pemukiman, persawahan dan tambak. Di bagian hilir 
terutama sekitar teluk Kendari penggunaan sudah sangat kompleks, umumnya didominasi oleh kawasan pemukiman, kawasan komersial, industri, infrastruktur perkotaan dan fasilitas sosial (Sahabuddin, dkk, 2014).

Potensi pemanfaatan sungai Wanggu hingga saat ini yang utama adalah sebagai sumber air baku PDAM, selanjutnya pertanian, tambak dan rekreasi. Adapun perhitungan debit andalan Sungai Wanggu berdasarkan data tahun 2010-2019 disajikan pada Tabel 6.

Tabel 6. Debit Sungai Wanggu dalam Satu Tahun

\begin{tabular}{llc}
\hline No & Bulan & Debit (m3/liter) \\
\hline 1 & Januari & 0,78 \\
2 & Februari & 1,85 \\
3 & Maret & 1,11 \\
4 & April & 10,55 \\
5 & Mei & 4,87 \\
6 & Juni & 3,33 \\
7 & Juli & 3,33 \\
8 & Agustus & 1,9 \\
9 & September & 1,18 \\
\hline
\end{tabular}

\begin{tabular}{llc}
\hline No & Bulan & Debit (m3/liter) \\
\hline 10 & Oktober & 0,71 \\
11 & November & 0,77 \\
12 & Desember & 0,68 \\
\hline
\end{tabular}

Sumber: PDAM Tirta Anoa

Tabel 6 diketahui pada bulan-bulan Maret, April, Mei debit sungai Wanggu maksimal, sementara bulan Oktober dan November debitnya mengecil. Perhitungan debit yang dilakukan pada bulan Juli 2016 didapatkan sebesar 2,7325 m3/dtk atau 2.732,5 ltr/dtk. Saat ini, kapasitas terpasang Sungai Wanggu adalah 20 ltr/dtk dan kapasitas produksi adalah juga 20 ltr/dtk. Hal ini menunjukkan bahwa pemanfaatan debit Sungai Wanggu sangat kecil dibandingkan dengan ketersediaan debit sungai. Saat ini, Sungai Wanggu melayani 678 SR atau populasi sebanyak 3.390 orang yang membutuhkan air sebanyak 4.65 liter/detik. Dalam hal ini debit kapasitas produksi Sungai Wanggu cukup untuk melayani kebutuhan air pelanggan (Tabel 7).

Tabel 7. Kualitas Air Sungai Wanggu

\begin{tabular}{llllllllll}
\hline & $\begin{array}{l}\mathrm{pH} \\
(0 / 00)\end{array}$ & $\begin{array}{l}\text { TDS } \\
(\mathrm{mg} / \mathrm{L})\end{array}$ & $\begin{array}{l}\text { Kekeruan } \\
(\mathrm{NTU})\end{array}$ & $\begin{array}{l}\text { Klorida } \\
(\mathrm{mg} / \mathrm{L})\end{array}$ & $\begin{array}{l}\text { Nitrat } \\
(\mathrm{mg} / \mathrm{L})\end{array}$ & $\begin{array}{l}\text { Nitrit } \\
(\mathrm{mg} / \mathrm{L})\end{array}$ & $\begin{array}{l}\text { Kesadahan } \\
(\mathrm{mg} / \mathrm{L})\end{array}$ & $\begin{array}{l}\text { Fe } \\
(\mathrm{mg} / \mathrm{L})\end{array}$ & $\begin{array}{l}\text { E- } \\
\text { Coli }\end{array}$ \\
\hline Standar & $6-9$ & 1000 & 50 & 600 & 0,5 & 0,06 & $0,75 *$ & 0,3 & 1000 \\
Sampel & 6,54 & 124 & 48,9 & 0,0014 & 0,228 & 0,047 & 0,46 & 0,29 & 390 \\
\hline
\end{tabular}

Sumber: Hasi Olah Data

Berdasarkan pemeriksaan terhadap beberapa kualitas air di Sungai Wanggu, diketahui bahwa kualitas mata air Sungai Wanggu sebagai air kelas I yang diperuntukkan untuk air bersih dikategorikan kurang baik, karena parameter kualitas air kekeruhan dan nilai Fe mencapai nilai maksimum pada standar dan parameter kualitas air seperti Nitrat, Nitrit dan Kesadahan perlu diperhatikan karena nilainya mencapai setengah dari batas maksimum yang diperbolehkan dalam standar.

- Mata Air Anduonohu dan Anggoeya

Berdasarkan hasil pengukuran debit yang dilakukan pada bulan Juli 2016 didapatkan debit mata air Anduonohu adalah 0,0229 atau 22,9 ltr/dtk dan mata air Anggoeya adalah 0,059 m3/s atau 59,5 ltr/dtk. Kapasitas terpasang mata air Anduonohu adalah 5 ltr/dtk dan kapasitas produksi juga 3 ltr/dtk sedang kapasitas terpasang mata air Anggoeya adalah 25 ltr/dtk dan kapasitas produksi juga 25 ltr/dtk. Dalam hal ini pemanfaatan debit mata air Anduonohu masih sangat kecil sedang pemanfaatan debit mata air Anggoeya dinilai sudah cukup.

Saat ini mata air Anduonohu dan Anggoeya melayani 2.212 SR atau populasi sebanyak 10.795 orang yang membutuhkan air sebanyak 14,8 liter per detik. Hal ini berarti bahwa kebutuhan air pelanggan PDAM dapat terpenuhi dikedua mata air ini (Tabel 8). 
Tabel 8. Kualitas Air Mata air Anduonohu dan Anggoeya

\begin{tabular}{llllllllll}
\hline & $\begin{array}{l}\text { pH } \\
(\mathbf{0} / \mathbf{0 0})\end{array}$ & $\begin{array}{l}\text { TDS } \\
(\mathbf{m g} / \mathbf{L})\end{array}$ & $\begin{array}{l}\text { Kekeruan } \\
(\mathbf{N T U})\end{array}$ & $\begin{array}{l}\text { Klorida } \\
(\mathbf{m g} / \mathbf{L})\end{array}$ & $\begin{array}{l}\text { Nitrat } \\
(\mathbf{m g} / \mathbf{L})\end{array}$ & $\begin{array}{l}\text { Nitrit } \\
(\mathbf{m g} / \mathbf{L})\end{array}$ & $\begin{array}{l}\text { Kesadahan } \\
(\mathbf{m g} / \mathbf{L})\end{array}$ & $\begin{array}{l}\text { Fe } \\
(\mathbf{m g} / \mathbf{L})\end{array}$ & $\begin{array}{l}\text { E- } \\
\text { Coli }\end{array}$ \\
\hline Standar & $6-9$ & 1000 & 50 & 600 & 0,5 & 0,06 & $0,75^{*}$ & 0,3 & 1000 \\
Anduonohu & 6,94 & 305 & 1,18 & 0,0007 & 0,083 & 0,042 & 0,28 & - & - \\
Anggoeya & 6,78 & 299 & 5,24 & 0,0007 & 0,122 & 0,042 & 0,43 & - & 75 \\
\hline
\end{tabular}

Sumber: Hasi Olah Data

- Potensi Air Tanah

Air tanah merupakan sumber daya alam yang ketersediaannya baik kuantitas (jumlah) maupun kualitas (mutu) sangat tergantung pada kondisi lingkungan, dimana proses pengimbuhan pengaliran dan pelepasan air tanah tersebut berlangsung pada suatu wadah yang disebut cekungan air tanah (groundwater basin). Oleh karena itu dapat dimengerti apabila landasan kebijakan dalam pengelolaan air tanah berbasis pada cekungan air tanah, sebagaimana telah ditetapkan di dalam UU No. 7 Tahun 2004 tentang Sumber Daya Air, Pasal 12 ayat (2). Berdasarkan pemahaman tentang sifat dan keberadaannya, cekungan air tanah tidak dibatasi oleh batas-batas administrasi suatu daerah. Artinya cekungan air tanah dapat berada dalam suatu wilayah kabupaten/kota terlampar lintas batas kabupaten/kota, lintas batas provinsi atau bahkan lintas batas negara. RTRW Provinsi Sulawesi Tenggara untuk CAT di wilayah administrasi Kota Kendari, seperti kutipan dari RTRW Provinsi Sulawesi Tenggara sebagaimana berikut :

a. CAT lintas provinsi yaitu CAT Lelewowo terdapat di :

1. Kabupaten Kolaka Utara di Provinsi Sulawesi Tenggara; dan

2. Kabupaten Luwu Timur di Provinsi Sulawesi Selatan.

b. CAT lintas kabupaten terdiri atas :

1. CAT Bungku terdapat di Kabupaten Konawe, Konawe Selatan, Kolaka dan Kolaka Timur

2. CAT Ranomeeto terdapat di Kota Kendari, Kabupaten Konawe dan Konawe Selatan;

3. CAT Rawua terdapat di Kabupaten Konawe, Konawe Selatan dan Kota Kendari;

4. CAT Ewolangka terdapat di Kabupaten Bombana dan Kolaka;
5. CAT Tinanggea terdapat di Kabupaten Konawe Selatan dan Bombana;

6. CAT Muna terdapat di Kabupaten Muna dan Buton;

7. CAT Lebo terdapat di Kabupaten Buton, Muna dan Buton Utara;

8. CAT Konde terdapat di Kabupaten Buton Utara dan Buton;

9. CAT Bau-Bau terdapat di Kota Baubau dan Kabupaten Buton; dan

10. CAT Bangbong terdapat di Kabupaten Buton Utara dan Muna.

Kota Kendari diidentifikasi memiliki potensi air tanah dangkal dan air tanah dalam. Uraian lebih rinci mengenai potensi air tanah di Kota Kendari adalah sebagai berikut :

a. Potensi air tanah dangkal meliputi :

1. Daerah rawan pasang surut.

2. Kedalaman air tanah kurang dari 3 $m$ dengan debit kurang dari 5 liter.

3. Kedalaman air tanah antara $3 \mathrm{~m}$ sampai $10 \mathrm{~m}$ dengan debit antara 3 liter/detik.

Adapun kondisi air tanah dangkal di wilayah Kota Kendari terdiri dari:

1. Air tanah dangkal dengan kedalaman air tanah 3-10 meter dan potensi aquifer sedang ( $3-5$ ltr/detik), tersebar di semua kecamatan Baruga, serta sebagian kecil di sebelah utara Kecamatan Mandonga;

2. Air tanah dangkal dengan kedalaman air tanah kurang dari 3 (tiga) meter dan potensi aquifer sedang ( > 5 ltr/detik), tersebar di 3 (tiga) kecamatan, yaitu di sekitar Teluk Kendari pada Kecamatan Poasia dan yaitu di sekitar Teluk Kendari pada Kecamatan Kendari, sedangkan di Kecamatan Mandonga mulai dari sisi timur 
atau kelurahan Korumba hingga ke arah selatan Kelurahan Watulondo, untuk di Kecamatan Baruga mulai dari Kelurahan Kadia ke arah selatan hingga sekitar Kelurahan Baruga dan di Kecamatan Poasia menyebar ke sebelah utara sebelum Teluk Kendari.

b. Potensi air tanah dalam diklasifikasi sebagai berikut :

1. Potensi aquifer sangat rendah dengan debit (Q) kurang dari 1 liter/detik.

2. Potensi aquifer rendah setempat dengan debit (Q) 1 liter/detik.

3. Potensi aquifer rendah sampai sedang dengan debit (Q) antara 1 sampai 3 liter/detik.

4. Potensi aquifer sedang sampai tinggi dengan parameter debit air (Q) antara 3 sampai 5 liter/detik.

Untuk kondisi air tanah dalam di wilayah Kota Kendari terdiri dari :

1. Air tanah dalam dengan potensi aquifer rendah setempat-tempatnya ( $<1$ ltr/detik), tersebar di semua kecamatan dengan penyebaran terluas di Kecamatan Poasia sekitar pegunungan Nipa-Nipa, serta di sebelah barat Kecamatan Mandonga dan Baruga, sedangkan di Kecamatan Kendari hanya bagian timur wilayah pesisir.

2. Air tanah dalam dengan potensi aquifer rendah (1 - 3 ltr/detik), tersebar di semua kecamatan. Jenis air tanah ini, mendominasi hampir seluruh wilayah Kecamatan kendari. Persebarannya di Kecamatan Poasia pada pegunungan Nipa-Nipa.

\section{Sistem Pelayanan PDAM Tirta Anoa Kota Kendari}

Sistem pelayanan PDAM Tirta Anoa Kota Kendari terdiri dari masing masing zona pelayanan, yaitu terdiri dari Unit SPAM PDAM Pusat/Pohara, SPAM IKK PDAM Matabondu, SPAM IKK PDAM Wanggu, dan SPAM PDAM Anggoeya/ Andounohu. Berikut penjelasan sistem jaringan perpipaan dari masing-masing zona pelayanan pada PDAM Tirta Anoa Kota Kendari.

\section{SPAM PDAM Pusat/Pohara}

\section{a. Unit Air Baku}

Hampir sebagian besar cakupan pelayanan PDAM Tirta Anoa Kota Kendari mengandalkan SPAM yang berasal dari punggolaka/pohara. SPAM PDAM Pusat/Pohara jenis sumber airnya yaitu air permukaan yang terdapat pada sungai Pohara. sumber air baku pada sungai pohara secara kontiunitas dapat mengalir terus karena pada musim kemarau sungai pohara ini kondisinya tidak kering. Debit airnya sangat besar mencapai 90.000 (l/dtk) dengan cakupan wilayah pelayanan meliputi Kecamatan Mandonga, Kecamatan Kendari, Kecamatan Kendari barat, Kecamatan Wua-wua, Kecamatan Kadia dan Kecamatan Puuwatu. Saat ini SPAM PDAM Pusat/Pohara eksisting sambungan rumah mencapai 15.275 SR.

Pada SPAM PDAM Pusat/Pohara ini memiliki intake untuk mengambil air baku dari Sungai Pohara. Sebelum intake Sungai Pohara dan Instalasi Pengolahan Air (IPA) Punggolaka dibangun dan beroperasi pada tahun 1980, sumber air baku PDAM Tirta Anoa Kota Kendari berasal dari air permukaan yang disadap langsung dengan pompa dan dialirkan dengan pipa transmisi menuju konsumen tanpa menggunakan IPA. Lokasi sumber ini terletak di wilayah Gunung Jati dengan area pelayanan meliputi Gunung Jati, Sodohoa, dan Kendari. Namun karena keterbatasan sumber air Gunung Jati dan kebutuhan area pelayanan yang terus meningkat, maka PDAM Tirta Anoa Kota Kendari mengupayakan pembangunan intake Sungai Pohara yang berjarak $17 \mathrm{~km}$ arah Barat dari pusat Kota Kendari sebagai sumber air baku. Lokasi intake Pohara terletak di Kecamatan Pohara Kabupaten Konawe.

Proses pengambilan air menggunakan Screw Pump yang dipasang pada bibir sungai dengan kedalaman tertentu melalui pintu masuk air. Fungsi pintu air ini adalah untuk mengontrol air yang masuk ke dalam bak agar tidak melebihi kapasitas yang diinginkan sehingga menyebabkan bak meluap. 
Screw Pump terdiri dari 2 unit dengan kapasitas total keduanya $400 \mathrm{l} / \mathrm{dtk}$ yang beroperasi sejak tahun 1997. Air yang telah masuk ke dalam bak ini langsung dipompa ke bak pengendapan dengan menggunakan 2 unit Screw Pump yang bekerja secara bergantian akibat daya listrik yang terbatas. Screw Pump ini menimba air dari sungai ke bak pengendapan, dengan kapasitas pompa terpasang adalah 400 ltr/dtk. Pompa ini digerakkan oleh motor penggerak dengan daya listrik yang dibutuhkan sebesar 800 Volt. Untuk lebih jelas lihat gambar dibawah.

Selain mesin Screw Pump terdapat juga 1 unit mesin pompa sub mersibel dengan kapasitas $400 \quad \mathrm{l} / \mathrm{dtk}$ untuk mendukung mesin Screw Pump dalam menganakut air baku dari sungai. Untuk teknisnya mesin sub mersibel ini digunakan secara bergantian dengan pompa Screw Pump. Air yang menuju di bak pengendap ini di pasangkan screen untuk memisahkan air jika ada kerikil, daun, atau pun kotorankotoran yang dapat merusak mesin pompa air. Pada tahap air baku menuju bak pengendap ini, tahap ini disebut pra sedimentasi. Karena air baku masih banyak mengandung lumpur dan tanah.

Setelah tahap pra sedimentasi di bak pengendapan, air baku dipompa menuju ke IPA Punggolaka. Mesin pompa terdiri dari 5 buah yaitu 2 unit merk Ebara, 2 unit merk KSB, dan 1 unit merk Paco. Kelima mesin pompa itu dalam kondisi baik.Sebelumnya dari bak pengendapan ini sebelum ke IPA punggolaka air baku melalui pipa transmisi dengan diameter $600 \mathrm{~mm}$ dialirkan dulu ke booster puwatu, akan tetapi booster puwatu untuk sekarang ini tidak beroperasi, karena dianggap peningkatan debit air tidak terlalu signifikan, olehnya itu, air baku dari Intake Pohara langsung saja di alirkan ke IPA Punggolaka.

Masalah terbesar pada Intake Pohara adalah jika listrik dari PLN padam. Oleh pihak PDAM sebenarnya sudah mengantisipasi masalah tersebut dengan mengadakan mesin genset listrik yang terdiri dari 3 unit, berbahan bakar solar. 3 mesin genset itu adalah 1 unit merk Perkins dengan kapasitas $1000 \mathrm{KW}$ pengadaan tahun 2005, 1 unit merk Perkins dengan kapasitas 500 KVA pengadaan tahun 1997, dan 1 unit merk Mercy dengan kapasitas 350 KVA pendagadaan tahun 1991. Kondisi sekarang dari 3 unit mesin genset ini dalam keadaan rusak.

b. Unit Produksi

Instalasi Pengolahan Air (IPA) ponggolaka terletak di Kecamatan Puuwatu Kelurahan Ponggolaka Kota Kendari. IPA ini merupakan proses penjernihan air dan hasilnya langsung disalurkan kepada masyarakat. Di WTP ini pengolahan air bersih melalui 4 tahap bagian yaitu : bak koagulasi, bak flokulasi, bak sedimentasi dan bak filtrasi yang berfungsi untuk mengolah air dari kulaitas air baku (influent) terkontaminasi untuk mendapatkan perawatan kualitas air yang diinginkan sesuai dengan standar mutu atau siap untuk dikonsumsi. Selain itu, untuk mendukung pengolahan air bersih di WTP, terdapat jenis pompa yang berbeda-beda fungsinya yaitu, pompa tawas, pompa kaporit, pompa tawas celup pompa washing pompa scrorr air blower, pompa pencuci, pompa pengisian larutan bahan kimia pompa doshing kapur, dan pompa vacum chamber. Untuk mendukung 4 bak pengolahan inti dari air bersih terdapat juga bak pengolahan water clean, bak chlorinasi, bak pelarutan tawas, bak pelarutan kaporit.

Pada akhir tahun 2018 Kapasitas reservoir Instalasi Pengolahan Air Punggolaka sebesar $2.500 \mathrm{~m} 3$. Seiring dengan adanya peningkatan jumlah penduduk dan perluasan wilayah permukiman, maka dilakukan evaluasi terhadap jumlah pelanggan yang ada di Kota Kendari. Berdasarkan hasil evaluasi diketahui bahwa kapasitas reservoir yang ada yaitu sebesar 2.500 M3 dibandingkan dengan jumlah pelanggan pada akhir tahun 2019 adalah sebesar 18.450 SR, hal ini menunjukkan ketidakmampuan kapasitas yang ada untuk mencukupi kebutuhan pelayanan air minum dalam wilayah Kota Kendari, sehingga lakukan strategi pelayanan yaitu dengan pelayanan buka tutup setiap zona pengaliran dengan durasi waktu pengaliran yaitu 1 kali dalam dua hari. 
c. Unit Transmisi

Sistem transmisi air baku Kota Kendari adalah Booster Puwatu. Booster Puwatu terletak di Kecamatan Puwatu Kota Kendari yang memiliki jarak $2 \mathrm{Km}$ dari IPA Punggolaka. Booster Puwatu dibangun pada tahun 1997 yang berfungsi untuk menambah tekanan air dari Intake Pohara menuju IPA Punggolaka. Di Booster Puwatu terdapat ruang staf dan terdapat 3 unit pompa dengan kapasitas terpasang masing-masing 200 ltr/dtk dan 1 (satu) unit Genset dengan kapasitas daya 800 KVA.

Booster Puwatu dilengkapi dengan reservoir bawah tanah yang berfungsi untuk menampung air yang berasal dari intake Pohara dan selanjutnya diteruskan ke IPA Punggolaka yang jaraknya kurang lebih 2 $\mathrm{km}$ dari tempat ini.Selain itu booster Puwatu dilengkapi pompa pendorong kapasitas 200 ltr/dtk yang berfungi untuk mendorong air yang terdapat di reservoir menuju ke IPA Punggolaka melalui pipa trasmisi berdiameter $600 \mathrm{~mm}$ dan sepanjang $2 \mathrm{Km}$.

Panjang Pipa Transmisi dari intake ke WTP sepanjang $17.000 \mathrm{~m}$ dengan mempergunakan pipa jenis DCIP, diameter $600 \mathrm{~mm}$. Disamping umur pipa yang sudah melampaui usia manfaat dan adanya pergeseran tanah pada areal rawa menyebabkan terjadinya kebocoran pipa transmisi.

Untuk saat ini, Booster Puwatu sudah tidak difungsikan lagi, karena fungsinya diharapkan untuk menambah tekanan air ke WTP punggolaka ternyata tidak memberikan dampak tekanan yang signifikan, sehingga oleh pihak PDAM dari pada biaya operasional (bahan bakar, gaji karyawan, maintenance) membengkak dari booster puwatu, air baku dari Intake Pohara dialirkan secara langsung saja ke WTP punggolaka.

d. Unit Distribusi

Sistem pendistribusian pada SPAM PDAM Pusat/Pohara dari Instalasi Pengolahan air (IPA) kepada masyarakat penggunan air minum dengan menggunakan sistem gravitasi dan pompa. Cakupan pelayanan distribusi meliputi Kecamatan Mandonga, Kecamatan
Kendari, Kecamatan Kendari barat, Kecamatan Wua-wua, Kecamatan Kadia dan Kecamatan Puuwatu. Karena terbatasnya produksi pengolahan air pada IPA Punggolaka sehingga selama lebih dari 5 tahun terakhir, penambahan cakupan pelayanan dari PDAM tidak terlalu signifikan. Hal ini terlihat dari tahun 20162018 hanya bertambah 2.241 SR atau 2,17 $\%$ setiap tahun.

Saat ini pencapaian volume distribusi pada SPAM PDAM Pusat/Pohara mencapai 5.244.141 m3 dengan volume terjual 2.369.696 m3, kehilangan air sebesar 2.874.445 m3. Jumlah total pelanggan 15.163 SR dengan jumlah pelanggan baru sebanyak 215 SR.

Reservoir punggolaka menjadi tempat penampungan air bersih dari IPA Punggolaka sebelum didistribusikan ke masyarakat. Satu reservoir dengan kapasitas $2500 \mathrm{~m} 3$ dibangun pada tahun 1978, kondisi sampai saat sekarang adalah kondisinya masih berfungsi dan baik. Satu reservoir dengan kapasitas $1500 \mathrm{~m}^{3}$ dibangun pada tahun 2010, dan 1 reservoir dengan kapasitas $4000 \mathrm{~m}^{3}$ yang dibangun pada tahun 2018.

Karena cakupan wilayah pelayanan sampai di kota lama, maka untuk mendukung distribusi dibangun juga 1 reservoir yang terdapat di Kendari Beach dengan kapasitas 1000 m3 yang dibangun pada tahun 1982 dan direnovasi pada tahun 2018. Kondisi revervoir tersebut masih berfungsi dengan baik

\section{SPAM PDAM Matabondu}

a. Unit Air Baku

Air baku Matabondu berasal dari mata air. Mata air ini secara wilayah masuk dalam wilayah kabupaten konawe, dan letak mata air Matabondu sangat dekat dengan sungai pohara. Kapasitas sumber air baku sebanyak 250 ltr/dtk, kapasitas terpasang sebanyak 50 ltr/dtk dan kapasitas produksi sebesar 35 ltr/dtk. Pada awalnya masyarakat yang menemukan sumber mata air tersebut. Karena di nilai sumber airnya melimpah, maka mata air Matabondu oleh pihak Balai Wilayah Sungai (BWS) Sulawesi IV dibuatkan intake untuk menangkap mata air tersebut. Intake dari 
matabondu sangat sederhana karena air yang berasal dari mata air sudah jernih dan layak di konsumsi secara langsung oleh masyarakat. Proses pengambilan air baku yaitu dari sunber mata air dibuatkan kanal menuju bak penampungan. Ukuran bak ini tidak terlalu besar yaitu sekitar $4 \mathrm{~m} \mathrm{x} 4 \mathrm{~m}$ dengan kedalaman sekitar 3 meter. Air bersih yang tertampung di bak langsung diisap melalui pompa yang letaknya tepat diatas bak penampungan. Pompa pada intake matabondu ini hanya 1 unit yaitu merk Capriari dengan kapasitas 100 l/dtk, tahun pengadaan tahun 2018. Fungsi dari pompa ini yaitu memompa air untuk langsung di alirkan di pipa distribusi. Kondisi pompa dalam keadaan berfungsi/baik. Untuk membantu kinerja pompa, pompa di gandengkan dengan motor pompa merk Siemens $100 \mathrm{KW}$, motor pompa ini pengadaan tahun 2015 dan kondisinya baik.

Saat ini sumber mata air di Matabondu banyak di gunakan langsung oleh masyarakat. Debit air yang terlihat tidak terlalu banyak. Kondisi bak penampungan air terisi cuma setengahnya dari ketinggian bak penampungan. Terlihat dilokasi banyak mesin pompa air milik masyarakat langsung mengambil di mata air. Air yang dari pompa tersebut dialirkan langsung melalui pipa-pipa kecil ukuran 3" langsung menuju rumah masyarakat.

Secara kepemilikan aset bangunan intake di Matabondu sepenuhnya di bangun oleh pihak Balai Wilayah Sungai Sulawesi IV. Pihak PDAM Tirta Anoa Kota Kendari hanya sebatas kerja sama dan berhak dalam hal pengelolaan.

b. Unit Produksi

Secara kualitas kondisi air bersih pada sumber air Matabondu sudah terlihat jernih dan bisa dapat langsung dikonsumsi oleh masyarakat. Pihak PDAM Tirta Anoa Kota Kendari juga telah melakukan tes alat tingkat kejernihan dan kandungan kimia dari air yang berasal dari mata air Matabondu dan hasilnya air tersebut layak dan bisa langsung dikonsumsi.

Olehnya itu, di Matabondu tidak terdapat IPA seperti di Punggolaka yang mengolah dan menjernihkan air baku dari
Pohara yang masih keruh karena mengandung banyak lumpur. Air bersih yang keluardari mata air dan ditampung di bak penampungan langsung dialirkan ke pipa distribusi.

c. Unit Distribusi

Sistem pendistribusian pada SPAM Matabondu menggunakan sistem pengaliran menggunakan pompa. Keadaan topografi Matabondu yang berbukit untuk saat ini menyebabkan pendistribusian ke masyarakat tidak maksimal. PDAM Tirta Anoa Kota Kendari telah memasang pipa distribusi sepanjang $12500 \mathrm{~m}$ yang terdiri dari pipa PVC $\varnothing 400 \mathrm{~mm}=2900 \mathrm{~m}$, pipa PVC ø $350 \mathrm{~mm}=4000 \mathrm{~m}$, pipa PVC ø 300 $=5609 \mathrm{~m}$. pipa distribusi tersebut terpasang sampai reservoir IPA Punggolaka yang berkapasitas $1500 \mathrm{~m}^{3}$. pada saat uji coba aliran air menuju ke reservoir Punggolaka timbul masalah karena masalah topografi dimana aliran air sangat membutuhkan waktu yang lama. Sehingga cara ini di nilai kurang maksimal.

PDAM Tirta Anoa Kota Kendari berencana untuk kedepan membuat jaringan distribusi yang baru untuk mengalirkan dari sumber mata air Matabondu menuju ke reservoir dengan kapasitas $3000 \mathrm{~m}^{3}$ yang terletak di dekat kantor camat Mandonga. Jika jaringan ini sudah terlaksana dan beroperasi, PDAM Tirta Anoa Kota Kendari dapat melayani wilayah sebagian Mandonga, dan Puuwatu.

d. Unit Pelayanan

Cakupan pelayanan saat ini dari mata air Matabondu hanya melayani Kecamatan Puuwatu yaitu kelurahan Tobuuha dan Kelurahan Lalodati. Sambungan rumah telah melayani sebanyak 627 SR. oleh pihak BWS Sulawesi IV membangun reservoir di dekat mata air Matabondu untuk mengalirkan langsung kerumahrumah penduduk.

\section{SPAM IKK PDAM Wanggu}

\section{a. Unit Air Baku}

Sumber air baku Unit IKK PDAM Wanggu bersumber dari air permukaan yang terdapat di sungai Wanggu. Debit air yang dihasilkan sebesar $200 \mathrm{ltr} / \mathrm{dtk}$. Unit PDAM Wangu ini memiliki Intake untuk 
mengalirkan air baku menuju WTP. Proses pengaliran air baku yaitu dibuatkan semacam sumur/ bak penangkap yang berdiameter kurang lebih 2 meter. Air baku dari sungai wanggu di alirkan sementara di sumur tersebut. Dari sumur ke rumah pompa terdapat pipa yang menuju kerumah pompa.

Pada intake IKK PDAM Wanggu terdapat rumah 1 pompa. Rumah pompa ini menampung 2 unit pompa yang di gunakan untuk mengisap air baku di sumur/bak penangkap. Untuk mendukung kinerja pompa, pompa juga d ihubungkan dengan genset yang terletak di rumah operator. Jumlah genset ini sebanyak 2 unit, 2 unit genset itu bermerk FG.Wilson dengan masing-masing kapasitas 60 KVA berfungsi sebagai penggerak pompa. Saat ini kondisi 1 mesin genset itu telah rusak dan hanya 1 unit saja dalam keadaan kondisi baik dan dapat beroperasi.

b. Unit Produksi

Air baku dari intake dialirkan melalui pipa sepanjang $2000 \mathrm{~m}$ menuju ke WTP Wanggu. Air baku yang berasal dari sungai wanggu memang memerlukan pengolahan karena fisik airnya yang masih keruh sehingga perlu adanya proses pengolahan agar menjadi jernih. Untuk mengolah air baku yang masih keruh perlakuan yang diberikan yaitu dengan mencampur air baku dengan tawas, kaporit, dan soda as. Pada WTP Wanggu kapasitas terpasang sebanyak $20 \mathrm{ltr} / \mathrm{dtk}$. Lama operasional selama 18 jam dengan kebutuhan listrik 22000 KVA. Pada WTP Wanggu ini air baku yang telah diolah dan telah layak untuk di konsumsi ditampung dulu ke reservoir dan setelah itu dapat didistribusikan kepada masyarakat melalui pipa distribusi. Volume reservoir yang ada di WTP Wanggu adalah $240 \mathrm{M}^{3}$ yang dibangun pada tahun 2008

c. Unit Distribusi

Air bersih dari reservoir di WTP Wanggu di distribusikan untuk melayani air bersih di wilayah Kecamatan Baruga, Kecamatan Wua-wua, dan Perumahan Lepo-Lepo Indah. Cara pengaliran dari WTP ke pipa distribusi dengan cara pemompaan dan gravitasi.
Distribusi air ke Pelayanan menggunakan pompa 2 unit, dengan kapasitas 20 l/dtk yang dipasang pada tahun 2012. Jaringan Distribusi Utama (JDU) menggunakan Pipa Galvanis dan Pipa PVC dengan diameter $150 \mathrm{~mm}$. Jaringan Distribusi Pembagi (JDB) menggunakan Pipa PVC dengan diameter $150 \mathrm{~mm}$, pemasangan jaringan pipa pada tahun 2008.

d. Unit Pelayanan

Cakupan pelayanan saat ini dari unit IKK PDAM Wanggu hanya melayani Kecamatan Baruga. Sambungan rumah telah melayani sebanyak 678 SR. Pelayanan distribusi unit Wanggu 2 tahun belakangan ini agak terganggu karena perkembangan Kota Kendari yang banyak melakukan pekerjaan pelebaran jalan, sehingga jaringan pipa distribusi terutama pipa primer dan sekunder banyak yang mengalami pecah.

\section{SPAM PDAM Anggoeya/Andounohu}

a. Unit Air Baku

Pengolahan unit air baku Unit PDAM Anggoeya jenis sumber air bakunya berasal dari Air Permukaan, sedangkan untuk Unit PDAM Andounohu jenis sumber air bakunya berasal dari Mata Air. Kapasitas terpasang pada air baku Anggoeya adalah 40l/dtk dan kepasitas produksinya juga 40 l/dtk. Kapasitas terpasang pada air baku Andounohu yaitu 5 l/dtk dan kapasitas produksinya adalah 3 l/dtk. Sistem pengalirannya dengan sistem pompa dan gravitasi. Meskipun terdiri dari 2 jenis sumber air baku yang berbeda tetapi SPAM PDAM Anggoeya dan Unit Andounohu dalam pengelolaannya di kelola secara bersama sama karena jarak antara keduanya tidak terlalu jauh.

Air baku dari intake dialirkan melalui pipa sepanjang $700 \mathrm{~m}$ menuju ke Bak Penampung di WTP Anggoeya. Air baku dari Intake pada saat musim kemarau langsung dialirkan ke Reservoir tanpa dilakukan Pengolahan, karena sudah jernih. Tetapi pada saat musim hujan tingkat kekeruhan air di Intake memerlukan pengolahan agar menjadi jernih. Untuk mengolah air baku yang masih keruh perlakuan yang diberikan yaitu dengan 
mencampur air baku dengan tawas, kaporit, dan soda as. Pada WTP Anggoeya, air baku yang telah diolah maupun yang langsung dari Mata Air dan telah layak untuk di konsumsi ditampung dulu ke reservoir dan setelah itu dapat didistribusikan kepada masyarakat melalui pipa distribusi. Volume reservoir yang ada di WTP Anggoeya adalah $700 \mathrm{M}^{3}$ yang dibangun pada tahun 1997.

Pada intake WTP Anggoeya terdapat 2 unit pompa submersible yang berfungsi mengisap air dan dialirkan ke IPA dengan kapasitas $40 \mathrm{ltr} /$ det. Operasional Pompa menggunakan Daya Listrik dan untuk menjaga pemadaman listrik oleh PLN, terdapat genset/generator 1 unit mrk FG. Wilson yang diadakan pada pengadaan tahun 2017. Kebutuhan listrik genset yaitu 120 Ampere, 2200 Volt. Kondisi Genset itu masih berfungsi baik.

Pada intake Andounohu terdapat 2 unit pompa yang berfungsi mengisap air dan dialirkan ke bak penangkap 1 unit dengan kapasitas. Untuk mengambil air baku dari sumber air di pasang 2 unit pipa merk standar galvanis dan PVC, pipa tersebut tahun pengadaan 2004 yang berfungsi untu mengalirkan air baku ke intake.

b. Unit Produksi

Guna peningkatan pelayanan PDAM Tirta Anoa Kota Kendari khususnya di Kecamatan Abeli, Kecamatan Nambo, Kecamatan Poasia dan Kecamatan Kambu, dibangun Instalasi Pengolahan Air (IPA) di daerah Anggoeya dengan sumber air baku yang berasal dari sungai Anggoeya dan mata air, dengan kapasitas produksi 40 ltr/det, dengan waktu operasi selama 24 jam. Instalasi Pengolahan Air (IPA) Anggoeya belum dapat berjalan dengan maksimal, dikarenakan kurangnya daya listrik untuk menjalankan 2 buah pompa secara bersamaan.

c. Unit Distribusi

Unit distribusi pada SPAM Anggoeya dan Andonouho cara pengalirannya melalui gravitasi dan pemompaan. Jumlah pompa untuk mendukung distribusi yaitu 2 unit. Spesifikasi dari pompa tersebut adalah merk TECO. Selain itu dimensi pipa jaringan distribusi utama mengunakan pipa diameter $150 \mathrm{~mm}$, jaringan pipa sekundernya menggunakan pipa dengan diameter $150 \mathrm{~mm}$, sedangkan pipa distribusi tersiernya menggunakan pipa diameter $100 \mathrm{~mm}, 75 \mathrm{~mm}$ dan $50 \mathrm{~mm}$. Kondisi pipa distribusi tersebut dalam keadaan berfungsi dengan baik. Pada titik tertentu terdapat water meter sebanyak 2 unit. Water Meter tersebut dipasang pada tahun 2012 dan 2014, berfungsi untuk mengecek jumlah debit air yang melalui Pipa. Juga untuk mengontrol apakah air yang ada di Pengolahan sama dengan di pipa distribusi, sehingga jika terjadi kebocoran dapat segera diketahui. Kondisi water meter tersebut dapat beroperasi dan baik.

d. Unit Pelayanan

Cakupan pelayanan pada Unit Anggoeya dan Andounohu sudah mencapai 2.212 SR. Wilayah layanan dari kedua unit ini adalah melayani 3 kecamatan diantaranya Kecamatan Poasia yang terdiri dari Kelurahan Andounohu, Kelurahan Rahandouna, Kelurahan Matabubu. Kecamatan Abeli yang terdiri dari Kelurahan Pudai, Kelurahan Lapulu, Kelurahan Abeli serta Kecamatan Kambu yang terdiri dari Kelurahan Kambu dan Kelurahan Lalolara. Jumlah pegawai yang bertugas pada kedua unit ini berjumlah 35 orang.

\section{KESIMPULAN}

Wilayah pelayanan Perusahaan Daerah Air Minum (PDAM) Tirta Anoa Kota Kendari terbagi menjadi 4 wilayah pelayanan yaitu IKK Pusat/Pohara, IKK Wanggu, IKK Matabondu, dan IKK Anduonohu dan Anggoeya. Ketersediaan air bersih baku pada PDAM Kota Kendari adalah debit produksi sebesar 300 ltr/detik, debit produksi Mata Air Matabondu sebesar 50 l/detik, debit produksi Sungai Wanggu sebesar 20 l/detik, dan debit Mata air Anduonohu sebesar $5 \mathrm{ltr} / \mathrm{dtk}$ dan Anggoeya sebesar 40 ltr/dtk.

Ucapan Terima Kasih: Penelitian ini dapat terlaksana dengan baik atas bantuan dari pihak PDAM Kota Kendari, yang telah bersedia untuk 
berdiskusi dan memberikan data untuk kelengkapan penelitian ini. Kepada semua pihak yang telah membantu kami ucapkan terimakasih.

\section{DAFTAR PUSTAKA}

Baco La, Kahirun, Umar Ode Hasani, dan Abdul Jalil, 2017. Analisis Ketersediaan dan Kebutuhan Air di Daerah Aliran Sungai Roraya Provinsi Sulawesi Tenggara. Ecogreen 3(1): 1 - 8

BPPSPAM. 2010. Petunjuka Teknis Penilaian Kinerja PDAM Kementerian Pekerjaan Umum Badan Pendukung Pengembangan Sistem Penyediaan Air Minum. BPPSPAM. Jakarta

Lestari, A.S., Aditiajaya, Widianingsih E dan Dharmawan H. 2009. Monioring Kualitas Air Oleh Masyarakat. USAID. Jakarta
Sahabuddin, Hartina, Donny Harisuseno, dan Emma Yuliani. 2014. Analisa Status Mutu Air Dan Dayatampung Beban Pencemaran Sungai Wanggu Kota Kendari. Jurnal Teknik Pengairan, 5(1): 19-28

Sutrisno, Totok. 2004. Penyediaan Air Minum. Rinek Cipta. Jakarta

Syofyan, Z., 2017. Analisa Ketersediaan Air Bersih untuk Kebutuhan Penduduk di Kecamatan Pauh Kota Padang. Seminar Nasional Strategi Pengembangan Infrastruktur ke-3 (SPI-3) Institut Teknologi Padang, 27 Juli 2017 ISBN: 978-602-70570-6-7

Thuram, Gunter, dkk, 1995, Experience in Development of Small-Inter Scale Water Resources in Rural Areas, Proceeding of The Internasional Symposium on Development of Small Scale Water Resources in Rural Areas, Bangkok. 